А. О. Москаленко ${ }^{1}$, Г. В. Сокол ${ }^{2}$, Ю. В. Глуховець ${ }^{1}$, В. В. Варич ${ }^{1}$

${ }^{1}$ Полтавський інститут бізнесу ПВНЗ «Міжнародний науково-технічний університет імені академіка Юрія Бугая», Полтава, Україна

${ }^{2}$ Національний університет «Полтавська політехніка імені Юрія Кондратюка», Полтава, Україна

\title{
МАТЕМАТИЧНА МОДЕЛЬ ФОРМУВАННЯ СИГНАЛІВ 3 АДАПТАЦІЕЮ ПО ШВИДКОСТІ ПЕРЕДАВАННЯ ІНФОРМАЦІї НА ОСНОВІ ДОСКОНАЛИХ ДВІЙКОВИХ МАТРИЦЬ
}

\begin{abstract}
Анотація. Предметом дослідження є методи та моделі формування сигналів адаптивних видів модуляції. Мета: забезпечення високої пропускної здатності та спектральної ефективності, для даних умов розповсюдження радіохвиль, шляхом використання запропонованої моделі формування сигналів 3 адаптацією по швидкості передавання інформації на основі досконалих двійкових матриць. Результати досліджень. В роботі представлено результати аналізу напрямів розвитку та основних властивостей безпроводових мереж передачі даних. Встановлено, що лише у разі забезпечення комплексу розглянутих властивостей, безпроводова мережа може виконувати своє функціональне призначення - забезпечувати доставляння повідомлень у необхідному обсязі й із заданою якістю. Розглянуто принципи реалізації методів адаптивної модуляції в перспективних засобах бездротового зв'язку. Використання адаптивної модуляції дозволяє забезпечити найкращу пропускну здатність для даних умов розповсюдження радіохвиль, розглянута в роботі схема адаптивної модуляції дозволить звести ймовірність виникнення помилки в передачі до мінімуму. Запропоновано математичну модель формування сигналів з адаптацією по швидкості передавання інформації на основі досконалих двійкових матриць. Розглянуто основні принципи функціонування пристрою управління моделі формування сигналів з адаптацією по швидкості передавання інформації на основі досконалих двійкових матриць. Висновки та область застосування результатів досліджень. Запропонована математична модель формування сигналів з адаптацією по швидкості передавання інформації на основі досконалих двійкових матриць. Використання запропонованих сигналів з адаптацією по швидкості передавання інформації на основі досконалих двійкових матриць дозволить забезпечити високу пропускну здатність та спектральну ефективність, для даних умов розповсюдження радіохвиль, перспективних радіоінтерфейсів.
\end{abstract}

Ключов і слов а: мережі безпроводового зв'язку, модуляція циклічним зсувом коду, адаптивна модуляція, досконалі двійкові матриці.

\section{Вступ}

Постановка проблеми. Відповідно до [1] основними напрямами розвитку телекомунікацій в Україні є: створення сучасних широкосмугових мультисервісних транспортних мереж на основі єдиних протоколів, сумісних 3 інтернет-протоколами; розвиток широкосмугового абонентського доступу 3 використанням перспективних технологічних рішень; прискорене запровадження радіотехнологій рухомого зв'язку та використання систем абонентського радіодоступу; модернізація та розвиток спеціальних телекомунікаційних мереж для задоволення потреб національної безпеки та оборони держави - мереж Державної системи урядового зв'язку, національної системи конфіденційного зв'язку, спеціальної позаміської мережі зв'язку, мереж Воєнної організації держави; забезпечення мереж рухомого телефонного зв'язку за допомогою поступового переходу до мереж наступних поколінь 3 конвергенцією інформаційних, мультимедійних, телекомунікаційних та комп’ютерних технологій і послуг; інше.

Під час передачі даних безпроводовими каналами виникає багато труднощів, пов'язаних із впливом природних, промислових та навмисних завад (шумова загороджувальна завада, шумова завада в частині смуги, завада у відповідь, полігармонійна завада, комбінована завада тощо). Тому, для забезпечення розвитку перерахованих напрямів виникає необхідність у пошуку нових підходів щодо організації передавання інформації в мережах без проводового зв'язку.
Аналіз останніх досліджень і публікацій. У процесі функціонування на без проводові мережі (як загального користування, так і спеціального призначення) та ï елементи впливають різні фактори, що порушують іï нормальну роботу. Вони призводять до порушення роботи ліній зв'язку, фізичного виходу $з$ ладу елементів безпроводових мереж, інших негативних наслідків, у результаті чого вони переходить до такого стану, за якого вона не може забезпечувати процес доставки повідомлень (або не в змозі забезпечити цей процес за заданими параметрами). Таким чином, мережа повинна мати здатність протистояти впливам, які порушують її роботу, що забезпечується властивістю стійкості [2-8]. Важливо відзначити, що, лише маючи необхідну стійкість, безпроводова мережа може забезпечити задану своєчасність зв'язку, стійкість і безперервність управління.

Крім того, під час функціонування доставляння повідомлень може порушуватися не тільки факторами, що безпосередньо впливають на роботу системи зв'язку в цілому. В цих умовах мережа повинна мати здатність адаптації до всіх змін як зовнішніх, так і внутрішніх факторів, особливо структурних змін, що визначаються тим, за якими показниками мережа має властивість мобільності [2-8].

На підставі викладеного, можна зробити висновок, що тільки у разі забезпечення розглянутих вище властивостей, безпроводова мережа може виконувати своє функціональне призначення - забезпечувати доставляння повідомлень у необхідному обсязі й із заданою якістю. 
Мета статті. Враховуючи це, метою статті $\epsilon$ забезпечення високої пропускної здатності та спектральної ефективності, для даних умов розповсюдження радіохвиль, шляхом використання запропонованої моделі формування сигналів 3 адаптацією по швидкості передавання інформації на основі досконалих двійкових матриць.

\section{Реалізація методів адаптивної модуляції в перспективних засобах безпроводового зв'язку}

Принцип динамічної адаптивної модуляції полягає у наступному. На передавачі відбувається аналіз параметрів каналу передачі інформації. Потім передавач автоматично адаптує схему модуляції для отримання максимальної швидкості передачі інформації для даних умов.

Варіант практичної реалізації даного підходу представлений на рис. 1. Приймально-передавальний пристрій, що реалізований на обчислювальному пристрої, приймає вхідний сигнал від вузла, якому необхідно передати інформацію. Образ вхідного сигналу відомий завчасно. Цей вхідний сигнал оброблюється на узгодженому фільтрі, в результаті чого формується співвідношення сигнал/шум. При оцінюванні даного співвідношення в приймальнопередавальному пристрої здійснюється вибір порядку модуляції вихідного сигналу.

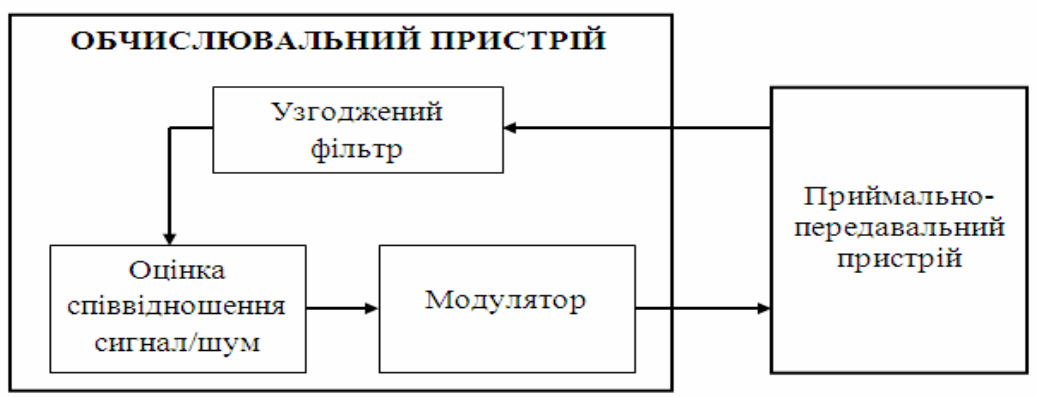

Рис. 1. Варіант схеми адаптивної модуляції

Використання адаптивної модуляції дозволяє забезпечити найкращу пропускну здатність для даних умов розповсюдження радіохвиль. Така схема адаптивної модуляції дозволить звести ймовірність виникнення помилки в передачі до мінімуму.

\section{Математична модель формування сигналів 3 адаптацісю по швидкості передавання інформації на основі досконалих двійкових матриць}

У загальному вигляді модель формування сигналів з адаптацією по швидкості передавання інформації на основі досконалих двійкових матриць (ДДМ) представлена на рис. 2.

Генератор ДДМ формує двовимірну досконалу двійкову матрицю розмірністю $n \times n$, де $n-$ кількість елементів у стовбцях і рядках матриці.

Порядок синтезу досконалих двійкових матриць розмірністю $n \times n$ приведено в [9].

У пристрої формування алфавіту сигналів відбуваються два перетворення:

- двовимірні циклічні зсуви синтезованої досконалої двійкової матриці розмірністю $n \times n$;

- перетворення отриманих матриць в одновимірні послідовності.

Двовимірні циклічні зсуви синтезованої досконалої двійкової матриці розмірністю $n \times n$ відбуваються послідовно по рядкам і стовпцям матриці [10, $11]$.

Порядок циклічної перестановки досконалої двійкової матриці по стовпчиках і рядках представлено на рис. 3 .

На рис. 4 наведено приклад циклічної перестановки матриці розмірністю $4 \times 4$.

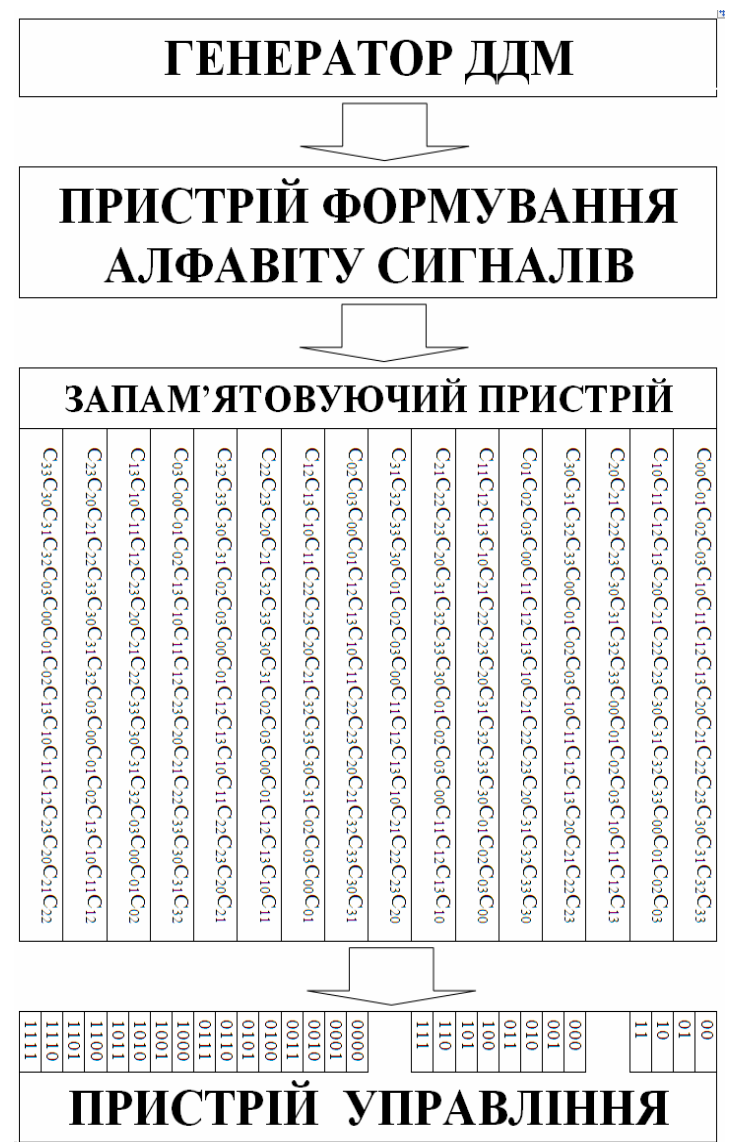

Рис. 2. Модель формування сигналів з адаптацією по швидкості передавання інформації на основі ДДМ

За результатами циклічних перестановок матриці розмірністю $n \times n$ можна отримати $n^{2}$ циклічних перестановок. 


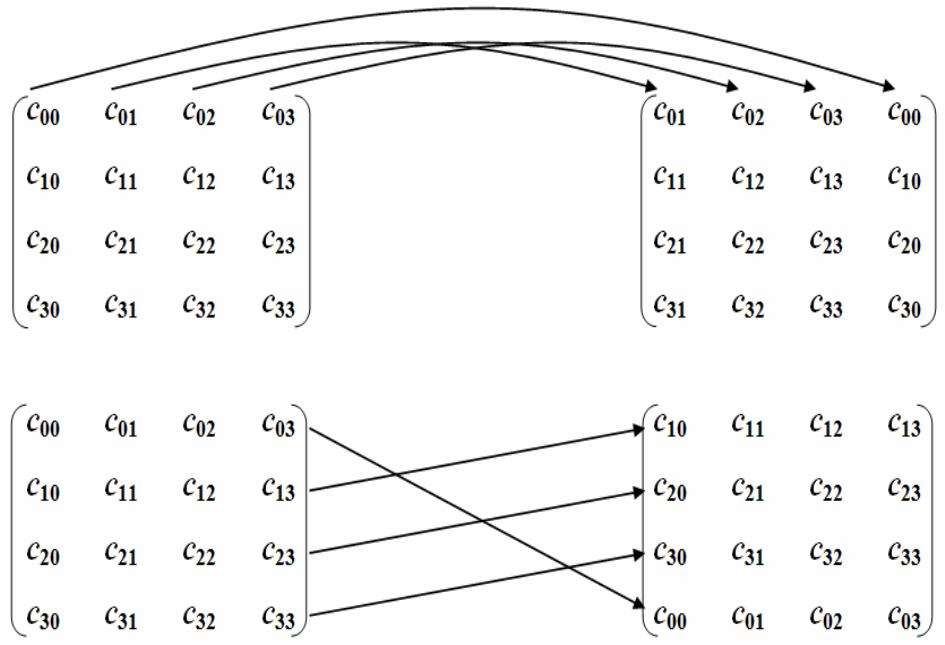

Рис. 3. Порядок циклічної перестановки ДДМ по стовпчиках і рядках

$\begin{array}{llllllllllllllllllllll}\mathrm{C}_{00} \mathrm{C}_{01} \mathrm{C}_{02} \mathrm{C}_{03} & \mathrm{C}_{01} \mathrm{C}_{02} \mathrm{C}_{03} \mathrm{C}_{00} & \mathrm{C}_{02} \mathrm{C}_{03} \mathrm{C}_{00} \mathrm{C}_{01} & \mathrm{C}_{03} \mathrm{C}_{00} \mathrm{C}_{01} \mathrm{C}_{02}\end{array}$ $\begin{array}{lll:l}\mathrm{C}_{10} \mathrm{C}_{11} \mathrm{C}_{12} \mathrm{C}_{13} & \mathrm{C}_{11} \mathrm{C}_{12} \mathrm{C}_{13} \mathrm{C}_{10} & \mathrm{C}_{12} \mathrm{C}_{13} \mathrm{C}_{10} \mathrm{C}_{11} & \mathrm{C}_{13} \mathrm{C}_{10} \mathrm{C}_{11} \mathrm{C}_{12}\end{array}$ $\begin{array}{llllll}\mathrm{C}_{20} \mathrm{C}_{21} \mathrm{C}_{22} \mathrm{C}_{23} & \mathrm{C}_{21} \mathrm{C}_{22} \mathrm{C}_{23} \mathrm{C}_{20} & \mathrm{C}_{22} \mathrm{C}_{23} \mathrm{C}_{20} \mathrm{C}_{21} & \mathrm{C}_{23} \mathrm{C}_{20} \mathrm{C}_{21} \mathrm{C}_{22}\end{array}$ $\mathrm{C}_{30} \mathrm{C}_{31} \mathrm{C}_{32} \mathrm{C}_{33} \mathrm{C}_{31} \mathrm{C}_{32} \mathrm{C}_{33} \mathrm{C}_{30} \mathrm{C}_{32} \mathrm{C}_{33} \mathrm{C}_{30} \mathrm{C}_{31} \mathrm{C}_{33} \mathrm{C}_{30} \mathrm{C}_{31} \mathrm{C}_{32}$

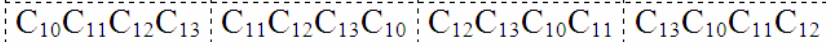
$\begin{array}{llllll}\mathrm{C}_{20} \mathrm{C}_{21} \mathrm{C}_{22} \mathrm{C}_{23} & \mathrm{C}_{21} \mathrm{C}_{22} \mathrm{C}_{23} \mathrm{C}_{20} & \mathrm{C}_{22} \mathrm{C}_{23} \mathrm{C}_{20} \mathrm{C}_{21} & \mathrm{C}_{23} \mathrm{C}_{20} \mathrm{C}_{21} \mathrm{C}_{22}\end{array}$ $\begin{array}{ll:llll}\mathrm{C}_{30} \mathrm{C}_{31} \mathrm{C}_{32} \mathrm{C}_{33} & \mathrm{C}_{31} \mathrm{C}_{32} \mathrm{C}_{33} \mathrm{C}_{30} & \mathrm{C}_{32} \mathrm{C}_{33} \mathrm{C}_{30} \mathrm{C}_{31} & \mathrm{C}_{33} \mathrm{C}_{30} \mathrm{C}_{31} \mathrm{C}_{32}\end{array}$ $\begin{array}{llllll}\mathrm{C}_{00} \mathrm{C}_{01} \mathrm{C}_{02} \mathrm{C}_{03} & \mathrm{C}_{01} \mathrm{C}_{02} \mathrm{C}_{03} \mathrm{C}_{00} & \mathrm{C}_{02} \mathrm{C}_{03} \mathrm{C}_{00} \mathrm{C}_{01} & \mathrm{C}_{03} \mathrm{C}_{00} \mathrm{C}_{01} \mathrm{C}_{02}\end{array}$ $\begin{array}{lllllllllllllllllll}\mathrm{C}_{20} \mathrm{C}_{21} \mathrm{C}_{22} \mathrm{C}_{23} & \mathrm{C}_{21} \mathrm{C}_{22} \mathrm{C}_{23} \mathrm{C}_{20} & \mathrm{C}_{22} \mathrm{C}_{23} \mathrm{C}_{20} \mathrm{C}_{21} & \mathrm{C}_{23} \mathrm{C}_{20} \mathrm{C}_{21} \mathrm{C}_{22}\end{array}$ $\begin{array}{llllll}\mathrm{C}_{30} \mathrm{C}_{31} \mathrm{C}_{32} \mathrm{C}_{33} & \mathrm{C}_{31} \mathrm{C}_{32} \mathrm{C}_{33} \mathrm{C}_{30} & \mathrm{C}_{32} \mathrm{C}_{33} \mathrm{C}_{30} \mathrm{C}_{31} & \mathrm{C}_{33} \mathrm{C}_{30} \mathrm{C}_{31} \mathrm{C}_{32}\end{array}$ $\begin{array}{lllllll}\mathrm{C}_{00} \mathrm{C}_{01} \mathrm{C}_{02} \mathrm{C}_{03} & \mathrm{C}_{01} \mathrm{C}_{02} \mathrm{C}_{03} \mathrm{C}_{00} & \mathrm{C}_{02} \mathrm{C}_{03} \mathrm{C}_{00} \mathrm{C}_{01} & \mathrm{C}_{03} \mathrm{C}_{00} \mathrm{C}_{01} \mathrm{C}_{02}\end{array}$ $\begin{array}{llllll}\mathrm{C}_{10} \mathrm{C}_{11} \mathrm{C}_{12} \mathrm{C}_{13} & \mathrm{C}_{11} \mathrm{C}_{12} \mathrm{C}_{13} \mathrm{C}_{10} & \mathrm{C}_{12} \mathrm{C}_{13} \mathrm{C}_{10} \mathrm{C}_{11} & \mathrm{C}_{13} \mathrm{C}_{10} \mathrm{C}_{11} \mathrm{C}_{12}\end{array}$ $\begin{array}{lllllllllllllllllllllll}\mathrm{C}_{30} \mathrm{C}_{31} \mathrm{C}_{32} \mathrm{C}_{33} & \mathrm{C}_{31} \mathrm{C}_{32} \mathrm{C}_{33} \mathrm{C}_{30} & \mathrm{C}_{32} \mathrm{C}_{33} \mathrm{C}_{30} \mathrm{C}_{31} & \mathrm{C}_{33} \mathrm{C}_{30} \mathrm{C}_{31} \mathrm{C}_{32}\end{array}$ $\begin{array}{llllll}\mathrm{C}_{00} \mathrm{C}_{01} \mathrm{C}_{02} \mathrm{C}_{03} & \mathrm{C}_{01} \mathrm{C}_{02} \mathrm{C}_{03} \mathrm{C}_{00} & \mathrm{C}_{02} \mathrm{C}_{03} \mathrm{C}_{00} \mathrm{C}_{01} & \mathrm{C}_{03} \mathrm{C}_{00} \mathrm{C}_{01} \mathrm{C}_{02}\end{array}$ $\begin{array}{lllllll}\mathrm{C}_{10} \mathrm{C}_{11} \mathrm{C}_{12} \mathrm{C}_{13} & \mathrm{C}_{11} \mathrm{C}_{12} \mathrm{C}_{13} \mathrm{C}_{10} & \mathrm{C}_{12} \mathrm{C}_{13} \mathrm{C}_{10} \mathrm{C}_{11} & \mathrm{C}_{13} \mathrm{C}_{10} \mathrm{C}_{11} \mathrm{C}_{12}\end{array}$ $\mathrm{C}_{20} \mathrm{C}_{21} \mathrm{C}_{22} \mathrm{C}_{23} \mathrm{C}_{21} \mathrm{C}_{22} \mathrm{C}_{23} \mathrm{C}_{20} \mathrm{C}_{22} \mathrm{C}_{23} \mathrm{C}_{20} \mathrm{C}_{21} \mathrm{C}_{23} \mathrm{C}_{20} \mathrm{C}_{21} \mathrm{C}_{22}$

Рис. 4. Приклад циклічної перестановки матриці розмірністю $4 \times 4$

Тобто, для приведеного прикладу (рис. 4) отримано $4^{2}=16$ циклічних перестановок.

Далі відбувається перетворення отриманих матриць в одновимірні послідовності $[10,11]$. Ця процедура відбувається шляхом розгортання матриці по рядках. На рис. 5 приведений приклад розгортання матриці $4 \times 4$ по рядках

Далі, $n^{2}$ отриманих одновимірних послідовностей записуються у запам'ятовуючий пристрій (рис. 2).

В пристрої управління, в залежності від оціненого рівня співвідношення сигнал/шум, приймається рішення про швидкість передавання інформації.

Для прикладу, приведеного на рис. 2, сформовано 16 кодових послідовностей розмірністю 16 біт кожна.
Максимальна швидкість передавання інформації для даного випадку складає:

$$
V_{\text {max }}=\log _{2} N /(\tau \cdot N),
$$

де $\tau$ - протяжність чипа; $N$ - довжина послідовності розширення спектру сигналів; $V$ - швидкість передавання інформації.

Мінімальна швидкість передавання інформації для даного випадку складає (2):

$$
V_{\min }=\frac{1}{\tau \cdot N} .
$$

Для наведеного вище прикладу, максимальна i мінімальна швидкості передаванні інформації відповідно складуть:

$$
\begin{gathered}
V_{\max }=\frac{\log _{2} N}{\tau \cdot N}=\frac{\log _{2} 16}{\tau \cdot 16}=\frac{4}{\tau \cdot 16}=\frac{1}{\tau \cdot 4} \text { бiт } / \mathrm{c} ; \\
V_{\min }=\frac{1}{\tau \cdot N}=\frac{1}{\tau \cdot 16} \text { бiт/c. }
\end{gathered}
$$

При високому співвідношенні сигнал/шум, вхідний потік інформаційних біт розбивається на четвірки біт. Кожній, із 16 можливих варіантів, четвірці відповідає одна із 16 кодових послідовностей алфавіту сигналу. У відповідності до четвірки інформаційних біт, що надійшли, в пристрої управління обирається суворо закріплена кодова послідовність і здійснюється ііі передавання.

При зменшенні рівня співвідношення сигнал/шум, до наперед заданої межі, вхідний потік інформаційних біт розбивається на трійки біт.

Кожній, із 8 можливих, трійці біт відповідає дві кодові послідовності із алфавіту сигналів. Відповідні кодові послідовності для кожної трійки є унікальними і не повторюються.

$$
\begin{aligned}
& \mathrm{C}_{00} \mathrm{C}_{01} \mathrm{C}_{02} \mathrm{C}_{03} \\
& \mathrm{C}_{10} \mathrm{C}_{11} \mathrm{C}_{12} \mathrm{C}_{13} \\
& \mathrm{C}_{20} \mathrm{C}_{21} \mathrm{C}_{22} \mathrm{C}_{23} \\
& \mathrm{C}_{30} \mathrm{C}_{31} \mathrm{C}_{32} \mathrm{C}_{33}
\end{aligned} \Longrightarrow \mathrm{C}_{00} \mathrm{C}_{01} \mathrm{C}_{02} \mathrm{C}_{03} \mathrm{C}_{10} \mathrm{C}_{11} \mathrm{C}_{12} \mathrm{C}_{13} \mathrm{C}_{20} \mathrm{C}_{21} \mathrm{C}_{22} \mathrm{C}_{23} \mathrm{C}_{30} \mathrm{C}_{31} \mathrm{C}_{32} \mathrm{C}_{33}
$$

Рис. 5. Приклад розгортання матриці $4 \times 4$ по рядках 
У відповідності до прийнятої трійки інформаційних біт, пристрій управління обирає дві кодові послідовності і здійснює їх послідовне передавання. При подальшому зменшенні рівня співвідношення сигнал/шум, до наступної наперед заданої межі, вхідний потік інформаційних біт розбивається на двійки біт. Кожній, із 4 можливих, двійці біт відповідає три кодові послідовності із алфавіту сигналів. Відповідні кодові послідовності для кожної двійки є унікальними і не повторюються. У відповідності до прийнятої двійки інформаційних біт, пристрій управління обирає три кодові послідовності і здійснює їх послідовне передавання. При подальшому зменшенні рівня співвідношення сигнал/шум, алгоритм роботи пристрою управління зберігається.

\section{Висновки}

Запропонована математична модель формування сигналів з адаптацією по швидкості передавання інформації на основі досконалих двійкових матриць. Швидкість передавання інформації для даних сигналів лежить в діапазоні

$$
\frac{1}{\tau \cdot N} \leq V \leq \frac{\log _{2} N}{\tau \cdot N} .
$$

Використання запропонованих сигналів 3 адаптацією по швидкості передавання інформації на основі досконалих двійкових матриць дозволить забезпечити високу пропускну здатність та спектральну ефективність, для даних умов розповсюдження радіохвиль, перспективних радіоінтерфейсів.

Напрямком подальших досліджень $є$ розробка порядку кореляційної обробки запропонованих сигналів, дослідження завадостійкості, структурної та енергетичної скритності сигналів 3 адаптацією по швидкості передачі інформації на основі досконалих двійкових матриць.

\section{СПИСОК ЛІтЕРАТУРИ}

1. Концепція розвитку телекомунікацій в Україні, схвалена Розпорядженням Кабінету Міністрів України від 7 червня 2006 р. № 316-p.

2. Кловский Д.Д. Передача дискретных сообщений по радиоканалам / Кловский Д.Д. - М.: Связь, 1969. -375 с.

3. Варакин Л.Е. Системы связи с шумоподобными сигналами / Варакин. Л.Е. -М.: Радио и связь, 1985. -384 с.

4. Варакин Л.Е. Теория систем сигналов / Варакин Л.Е. -М.: Советское радио, 1978. -304 с.

5. Теплов Н.Л. Теория передачи сигналов / Теплов Н.Л. -М.: Воениздат, 1976. -424 с.

6. Біла книга 2010: оборонна політика України / Під ред. Центру Разумкова. К.: МО, 2009. 120 с.

7. Указ президента України «Воєнна доктрина України» № 555/2015 від 24 вересня 2015 р.

8. Рудик В.В. Напрями та проблеми створення Єдиної автоматизованої системи управління Збройними силами України / В.В. Рудик // Наука і оборона. - 2006. - № 1. - С. 35 - 37.

9. Гепко И.А. Синтез совершенных двоичных решеток /И.А. Гепко // Радиоэлектроника (Изв. высш. учебн. заведений). - 1998. -T.41. - №6 - C. 13-21.

10. Shefer O. Analysis of efficiency of the bioinspired method for decoding algebraic convolutional codes / S. Panchenko, S. Prykhodko, S. Kozelkov, M. Shtompel, V. Kosenko, O. Shefer, O. Dunaievska / Eastern-European Journal of Enterprise echnologies 2/4 ( 98 ) 2019.

11. Гепко И.А. Новый класс ортогональных кодов для телекоммуникационных систем CDMA и метод их корреляционного приема, минимизирующий вычислительную сложность цифрового сигнального процессора /И.А. Гепко, А.А.Москаленко// Зв’язок. - 2007. - № 6. - С. 33-39.

12. Гепко И.А. Свойства ортогональных сигналов с прямым расширением спектра на основе совершенных двоичных матриц и алгоритма их корреляционной обработки /И.А. Гепко, А.А.Москаленко// Радиоэлектроника (Изв. вузов). 2008. - № 1-2. - C. 49-60.

\section{Mathematical model of signal generation with adaptation speed of information based on perfect binary matrices}

\section{A. Moskalenko, G. Sokol, Y. Gluhovets, V. Varich}

Abstract. Methods and models of signal generation of adaptive modulation types are the subject of the study. The purpose is providing high bandwidth and spectral efficiency for these radio wave propagation conditions by using the proposed signal generation model with adaptation rate information based on perfect binary matrices. Research results. The paper presents the results of an analysis of the development directions and basic properties of wireless data networks. It is established that only in case of providing the complex of the considered properties, the wireless network can fulfill its functional purpose - to provide delivery of messages in the required volume and with the set quality. The principles of the implementation of adaptive modulation methods in advanced wireless communications are discussed. The use of adaptive modulation allows to provide the best bandwidth for these radio wave propagation conditions, the adaptive modulation scheme discussed in this paper will minimize the probability of a transmission error. A mathematical model of signal generation with adaptation in the speed of information transfer based on perfect binary matrices is proposed. The basic principles of operation of the control device of the model of signal generation with adaptation on the speed of information transfer on the basis of perfect binary matrices are considered. Conclusions and scope of research findings. A mathematical model of signal generation with adaptation in the speed of information transfer based on perfect binary matrices is proposed. The use of the proposed signals with adaptation in the speed of information transmission on the basis of perfect binary matrices will allow to provide high bandwidth and spectral efficiency, for these conditions of propagation of radio waves and perspective radio interfaces.

Keywords: wireless networks, loopback modulation, adaptive modulation, perfect binary matrices. 